\title{
A decade of growth hormone treatment in girls with Turner syndrome in the UK
}

P R Betts, G E Butler, M D C Donaldson, D B Dunger, D I Johnston, C J H Kelnar, J Kirk, D A Price, P Wilton, the UK KIGS Executive Group on behalf of the participating centres

Southampton General Hospital, Southampton, UK P R Betts

Department of Paediatric and Adolescent Endocrinology, Leeds General Infirmary,

Leeds, UK

G E Butler

Department of Child Health, Royal Hospital for Sick Children, Yorkhill, Glasgow, UK M D C Donaldson

Department of Paediatrics, John Radcliffe Hospital, Headington, UK D B Dunger

Children's Department, University Hospital, Queen's Medical Centre, Nottingham, UK

D I Johnston

Royal Hospital for Sick Children, Edinburgh, UK

C J H Kelnar

The Birmingham Children's Hospital, Ladywood Middleway, Birmingham, UK J Kirk

Royal Manchester Children's Hospital, Pendlebury,

Manchester, UK

D A Price

Pharmacia and Upjohn, Stockholm, Sweden

P Wilton

Correspondence to: Dr P R Betts, Southampton General Hospital, Tremona Road, Southampton SO16 6YD, UK

Accepted 8 October 1998

\begin{abstract}
Fifteen per cent of children treated with growth hormone (GH) are receiving treatment for Turner syndrome, but few results are available on final height in the UK. In this study, data were obtained from the UK KIGS database for 485 girls with Turner syndrome who were treated from 1986, allowing an audit of practice and outcome over 10 years. Over the decade, the mean age of starting growth hormone treatment fell from 10.4 to 8.5 years and the starting dose increased from 0.55 to $0.95 \mathrm{IU} / \mathrm{kg} /$ week. The frequency of injections increased from three to six or seven/ week. Some girls received suboptimal doses, which also differed depending on whether they were based on weight or surface area. To assess what height gain might be expected at final height, all 52 girls who were prepubertal at the start of treatment, which continued for four years or more, and who had reached final height or had a growth velocity $<2 \mathrm{~cm} /$ year were selected. Their mean gain in final height was $5.2 \mathrm{~cm}$ and the GH dose was $0.78 \mathrm{IU} /$ kg/week over 5.8 years. Final height gain correlated significantly with duration of treatment, total dose received, and first year response, which itself related to starting dose. This audit shows a changing pattern of treatment over the past decade, which in many instances has been inadequate. When treatment starts before puberty and continues through to final height, with a dose of $30 \mathrm{IU} / \mathrm{m}^{2} /$ week in six or seven injections, a mean increase in final height of $5 \mathrm{~cm}$ or more would be expected.

(Arch Dis Child 1999;80:221-225)
\end{abstract}

Keywords: growth hormone; Turner syndrome; height gain

Short stature is a recognised consequence of Turner syndrome with a mean reduction in adult height potential of approximately $20 \mathrm{~cm} .{ }^{1}$ Recombinant growth hormone $(\mathrm{GH})$ has been licensed for use in Turner syndrome since 1988 to promote an increase in height, and this accounts for some $15 \%$ of all children on $\mathrm{GH}$ treatment; however, there are no nationally recognised treatment recommendations.

In the UK there have been few publications on the final height of girls with Turner syndrome treated with $\mathrm{GH}$, and these have involved small patient numbers and have shown disappointing results. $^{23}$ A Scottish study showed no significant increase in final height as a result of $\mathrm{GH}$ treatment. However, other studies, reviewed by Donaldson ${ }^{4}$ have reported positive, although variable, changes in height gain at final height with various treatment regimens including $\mathrm{GH}$ alone, $\mathrm{GH}$ with the addition of oxandrolone or oestrogens, or oxandrolone alone. ${ }^{5}$ The greatest height achieved over predicted height was seen in those girls who were the youngest at the start of treatment and who were treated until final height was achieved.

Variation in treatment practice occurs and the advised dose of $\mathrm{GH}$ specified in the British National Formulary to be used in girls with Turner syndrome ranges from 0.6 to $1 \mathrm{IU} / \mathrm{kg} /$ week or from 18 to $30 \mathrm{IU} / \mathrm{m}^{2} /$ week, with no guide as to which is the more effective dose. ${ }^{6}$

The Pharmacia and Upjohn international growth database (KIGS) is an international postmarketing safety and efficacy register that allows GH prescribing centres the opportunity to review their prescribing practice and treatment outcome with national and international standards. The UK KIGS database holds anonymous data on 3096 children who have been enrolled since 1987, and 1802 of these are currently on treatment. It is estimated that some $40 \%$ of children treated with $\mathrm{GH}$ in the UK are entered into KIGS and $15 \%$ of these have Turner syndrome.

We studied girls with Turner syndrome in the UK KIGS database treated with GH in the decade 1987-96 and examined the changing pattern of their treatment. To assess the possible increase in final height following treatment we selected all those who were at final height, started treatment before puberty, and had been treated for at least four years. We identified this cohort as those most likely to show the greatest increase in their final height over that projected before treatment ${ }^{4}$ and, as discussed later, it represents the $50 \%$ of girls with Turner syndrome who are below the 0.4 th centile on the 1990 UK growth charts, and who should have been identified from height screening at school entry. ${ }^{8}$

\section{Patients and methods}

We identified all girls with Turner syndrome who had been entered into the KIGS international database from the UK in the years 1987-96 and analysed their auxological, clinical, and therapeutic data. We included an additional six girls who had been treated from 1984 and their data entered retrospectively. The 
diagnosis of Turner syndrome was confirmed on the basis of their karyotype. These girls had been on no fixed treatment protocols or any standard dose of GH over the decade. Oestrogen treatment was instigated for the induction of puberty at varying ages and investigations and ongoing surveillance were determined individually. Data from all patients had been entered into the main international database, preserving both anonymity and confidentiality of information for each clinic.

We defined the cohort of girls with Turner syndrome reaching final height as all those who were prepubertal at the start of $\mathrm{GH}$ treatment, who had been treated for a minimum of four years, and whose present height velocity was $<2$ $\mathrm{cm} /$ year. We compared the growth pattern of these girls treated with $\mathrm{GH}$ with the reported growth of girls with Turner syndrome who were not treated with $\mathrm{GH}$, as reported by Lyon et al. ${ }^{1}$

We took final adult height in untreated girls to be the height aged 20 years on the Lyon centile charts. Because girls treated with $\mathrm{GH}$ reach final height before those who are untreated, we took the final height standard deviation score (SDS) in treated girls as the height at their last measurement expressed as an SDS at age 20 years. We determined predicted adult height before treatment began by a projection of the pretreatment SDS centile to that aged 20 years. ${ }^{1}$

The results, where appropriate, are shown as mean (SD). Statistical analysis was by SAS version 6.12/AIX.

\section{Results}

Over the decade, 485 girls were entered into the database and their mean (SD) GH peak on a stimulation test before treatment was 28 (19) $\mathrm{mU} / 1$.

TRENDS IN TREATMENT

Over the period of our study there has been a small but significant reduction in the mean age that treatment began $(r=-0.16 ; \mathrm{p}=<0.001)$ from 10.4 to 8.5 (range, 2-19) years, and the starting dose of $\mathrm{GH}$ has increased significantly $(r=0.16 ; \mathrm{p}=<0.001)$ from 0.55 to 0.95 (range, $0.2-1.55$ ) IU/kg/week. The frequency of injections has increased from three to six or seven each week and, since 1995, no child has received fewer than five injections each week.

DOSE

Two methods of calculating $\mathrm{GH}$ dose have commonly been used in the UK, relating either to body weight or surface area. Analysis of the dosage received by all the children at the start of treatment shows that many, particularly in the 1980 s, received low doses by either regimen compared with prescribing guidelines. There was also a significant reduction in dosage received at the start of treatment in relation to age when expressed as IU/kg/week $(r=-0.41$; $\mathrm{p}=<0.001$ ) (fig 1). The younger children received relatively high doses and the older ones much lower doses.

The dose of GH prescribed for any one child differed depending on whether this was calculated in relation to body weight or surface area. Figure 2 shows the relation of body weight and



Figure 1 The relation between age at the start of growth hormone treatment and initial dose (IU/kg/week).

surface area to age for all girls at the start of their treatment, and from these data we calculated the mean weight and surface area at the ages of 5,10, and 15 years. This was then used to determine the mean dose of $\mathrm{GH}$ given either as $30 \mathrm{IU} / \mathrm{m}^{2} /$ week or as $1 \mathrm{IU} / \mathrm{kg} /$ week (table 1 ). Girls receiving their dose based on surface area received 33\% more $\mathrm{GH}$ than those based on weight at age 5 years, similar doses at age 10 years, and a reduction of $10 \%$ in their dosage at age 15 years. The weight and surface area of the girls differed in range by as much as $100 \%$ between the ages of 10 and 15 years and consequently very wide differences in doses were used between these ages depending upon body size.

GROWTH AND FINAL HEIGHT

Four hundred of the children had been treated for at least 12 months and 340 for at least two years. There was a significant gain in height SDS with each year of treatment but the absolute amount waned with each year of treatment. The mean (SD) change in height SDS in the first year was $+0.55(0.31)$ and over two years was $+0.91(0.44)$

Fifty two girls fulfilled the stated criteria for analysis of final height gain on $\mathrm{GH}$ treatment. Table 2 shows age, height SDS, GH dose, and number of injections each week at the start and end of treatment. The mean (SD) age of onset of puberty was $12.6(1.8)$ years, the mean (SD) dose of $\mathrm{GH}$ prescribed was 0.78 (0.15) IU/kg/

Table 1 Differences in growth hormone doses based on body surface area (30 IU $/ \mathrm{m}^{2} /$ week) or weight (1 IU/kg/week) at three ages

\begin{tabular}{llll}
\hline \multicolumn{4}{l}{ Age (years) } \\
\cline { 2 - 4 } & 5 & 10 & 15 \\
\hline Weight $(\mathrm{kg})$ & 14 & 28 & 40 \\
Surface $\operatorname{area}\left(\mathrm{m}^{2}\right)$ & 0.62 & 0.95 & 1.2 \\
Dose $(\mathrm{IU} / \mathrm{kg} /$ week $)$ & 14 & 28 & 40 \\
Dose $\left(\mathrm{IU} / \mathrm{m}^{2} /\right.$ week $)$ & 18.6 & 28.5 & 36.4 \\
Difference $(\%)$ & +33 & +2 & -10 \\
\hline
\end{tabular}



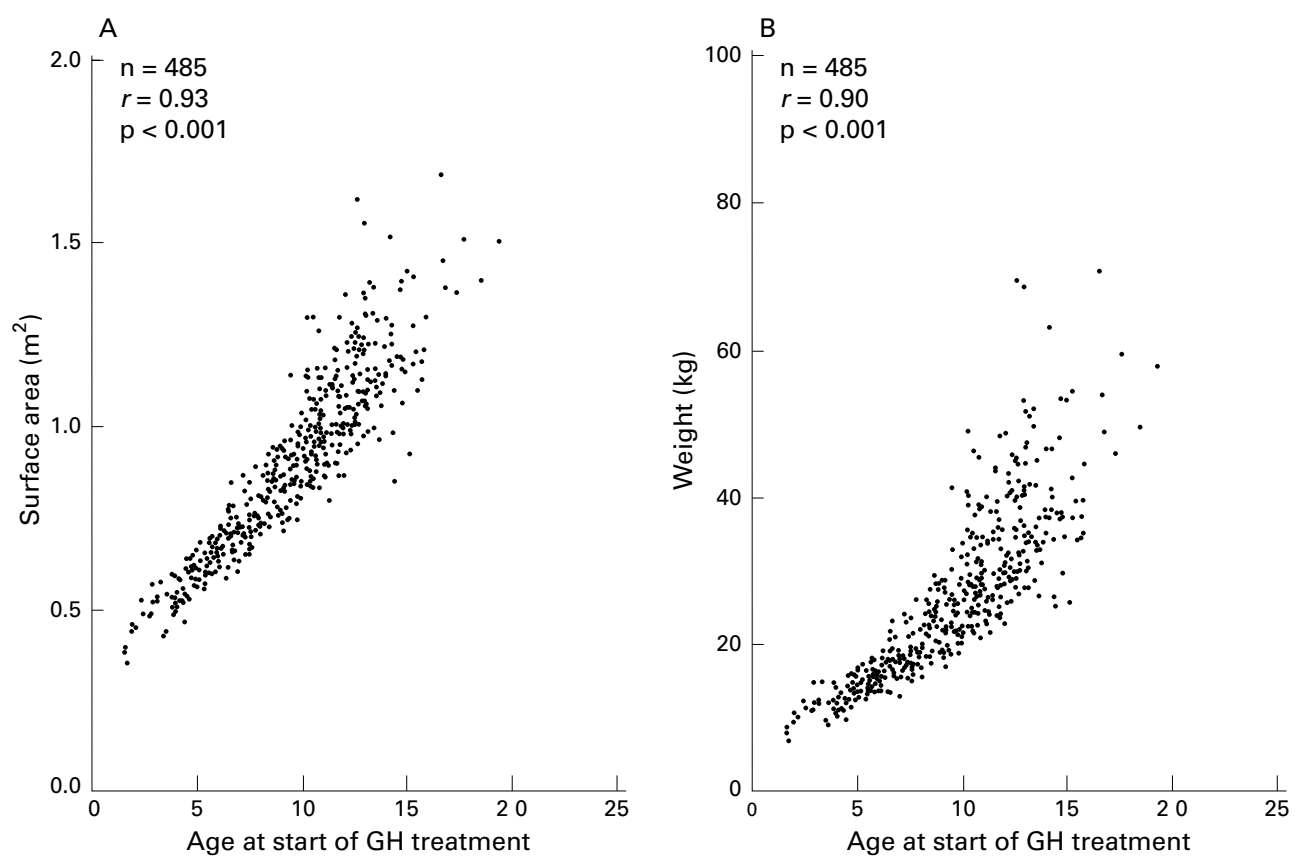

Figure 2 The relation between age, surface area, and weight at the start of treatment in all 485 girls.

week, the mean (SD) duration of treatment was 5.8 (1.1) years, and the last mean (SD) height velocity was $1.03(0.64) \mathrm{cm} /$ year. The mean (SD) total dose of $\mathrm{GH}$ received was 8474 (2334) IU.

Their mean (SD) change in height SDS in the first year of treatment was +0.61 (0.27) and over two years it was +1.05 (0.39). The mean (SD) increase in height SDS at final height was +0.62 (0.57), which equates to a height gain above projected height of $+4.15(3.8) \mathrm{cm}$.

LINEAR REGRESSION ANALYSIS

The increase in height SDS on GH treatment from start to final height in the 52 girls correlated significantly with the increase in height SDS in the first year of treatment (fig 3), the total time on GH treatment, and the total dose of $\mathrm{GH}$ received (table 3 ). The change in height SDS in the first year of treatment correlated significantly with the mean dose of $\mathrm{GH}$ given, both as $\mathrm{IU} / \mathrm{m}^{2} /$ week $\quad(r=0.43$; $\mathrm{p}=0.002)$ and as IU $/ \mathrm{kg} /$ week $(r=0.35$; $\mathrm{p}=0.011)$.

THE EFFECT OF AGE ON COMMENCING TREATMENT

To assess the effect on final height of starting treatment early, we divided the 52 girls into those starting treatment before $(n=14)$ and after $(n=38)$ the age of 10 years.

The mean (SD) height SDS for the 14 girls $<10$ years of age was $-0.49(0.87)$ at the start of treatment and $+0.25(0.95)$ at age 20 years.

Table 2 Details of children at the start and end of treatment

\begin{tabular}{lll}
\hline & Start of treatment & End of treatment \\
\hline Age (years) & $10.67(1.56)$ & $16.62(1.6)$ \\
Height (SDS) & $-0.2(0.87)$ & $0.42(0.88)$ age 20 \\
Dose of GH (IU/kg/week) & $0.74(0.26)$ & $0.78(0.15)$ \\
Injections/week (n) & $5.67(1.65)$ & $6.32(0.72)$ \\
\hline
\end{tabular}

Values are mean (SD). SDS values were calculated from Lyon et al. ${ }^{1}$
The 38 girls $>10$ years of age started treatment with a mean (SD) height SDS of -0.09 (0.85) and increased to $+0.48(0.86)$ at age 20 years.

Those treated from an earlier age reached their final height aged 15.8 years compared with those over the age of 10 years, who

Table 3 Change in height SDS (calculated from start to final height aged 20 years) on treatment in all 52 girls

\begin{tabular}{lll}
\hline & $\begin{array}{l}\text { Change in height SDS from } \\
\text { start to final height at } 20 \\
\text { years }\end{array}$ \\
\hline Change in height SDS first year & $r=0.453$ & $\mathrm{p}<0.001$ \\
Total time on GH & $r=0.318$ & $\mathrm{p}<0.02$ \\
Total units of GH received & $r=0.397$ & $\mathrm{p}<0.004$ \\
\hline
\end{tabular}

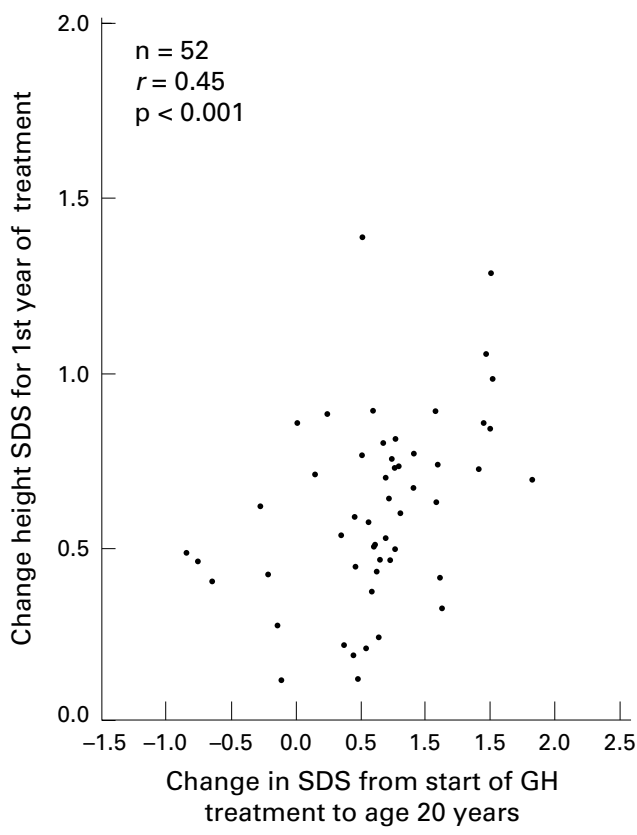

Figure 3 The relation between the change in height SDS in the first year of treatment and the change in height SDS from starting treatment to final height aged 20 years. 
reached final height aged 16.9 years. Those treated earlier had a mean (SD) change in height SDS at the age of 20 years of +0.74 (0.6), which is equivalent to $5.0(4.1) \mathrm{cm}$ greater than projected height. Those over the age of 10 years had a mean (SD) change in height SDS of $+0.58(0.6)$, which is equivalent to $3.9(4.0) \mathrm{cm}$ greater than projected height. Mean height velocity at the end of treatment for both groups was $1 \mathrm{~cm} /$ year; therefore, both groups would be expected to gain a further $1 \mathrm{~cm}$.

\section{Discussion}

Over the past decade, girls with Turner syndrome have been treated earlier in life, and the dose of $\mathrm{GH}$ and the number of injections given each week have increased. Presently, in the UK, the standard dose regimen for prepubertal children with $\mathrm{GH}$ deficiency is $15 \mathrm{IU} /$ $\mathrm{m}^{2} /$ week or $0.5 \mathrm{IU} / \mathrm{kg} /$ week in six to seven injections each week. ${ }^{6}$ Girls with Turner syndrome are not $\mathrm{GH}$ deficient and it has become usual practice to increase the dose to twice that used in GH deficiency. However, we note that even today some children are still treated with significantly suboptimal doses.

Most centres in the UK determine dose as $\mathrm{IU} / \mathrm{m}^{2}$ rather than $\mathrm{IU} / \mathrm{kg}$. Weight gain is a problem, particularly in older girls with Turner syndrome, and this will affect the dose of GH prescribed. Figure 2 demonstrates that the effect of calculating dose either by body weight or by surface area results in a considerable difference in the amount of $\mathrm{GH}$ prescribed. Using surface area, younger children would receive more and older children less, which partially explains why the younger children in fig 1 received such high doses and the older children had doses below that recommended. After the age of 10 years, the scatter of surface area and weight at any age is very wide, resulting in significant differences in the dose prescribed. Although there is little evidence available to support a recommendation of an optimal regimen, our results show that final height gain correlates with the first year growth response, which itself is related to the initial dosage used. This indicates that the initial higher dose based on surface area in the prepubertal girls might be of relevance. Van Teunenbroek et al reported that initial doses of $28 \mathrm{IU} / \mathrm{m}^{2} /$ week that were increased to 42 and $56 \mathrm{IU} / \mathrm{m}^{2} /$ week with advancing years resulted in improved height gain over the first four years. ${ }^{7}$ These data also support the use of a high dose for treatment.

The benefits of $\mathrm{GH}$ treatment on final height have been reported as variable. ${ }^{4}$ However, all these studies have used different regimens and the children have been at different ages when starting treatment. For this reason, meaningful comparative data are difficult to obtain. However, Donaldson ${ }^{4}$ reported a summary of 10 studies of girls treated with GH, who had reached final height, and showed that those who started treatment at a younger age and received it for a longer time achieved the greatest height gain. Our study included all girls treated for at least four years who were prepubertal at the start of treatment. We selected this cohort for two reasons. First, 50\% of girls with Turner syndrome should be identified at school entry because they are below the 0.4 th centile on height screening, so treatment could have started prepubertally. ${ }^{8}$ Second, they are the group likely to have benefited most from treatment and therefore provide an indication of the likely gain in final height to be expected with an adequate duration of treatment. As a group, their final height gain was modest, at just over $4 \mathrm{~cm}$, similar to other reported data. ${ }^{9}{ }^{10}$ However, a further $1 \mathrm{~cm}$ in height would still be expected in view of their continuing growth velocity. Although $5 \mathrm{~cm}$ is the mean increase in height gain, there is considerable individual variability between patients in their response, as shown by the large $\mathrm{SD}$ of $3.8 \mathrm{~cm}$. In addition, many of these girls commenced their treatment at the start of the decade with suboptimal doses and a reduced frequency of injections. Today, with these factors optimised, this gain in height should be greater.

The pattern of treatment in the initial year was an important determinant in the change in height SDS at final height. Some children grew poorly in this first year and, although this might be a result of poor compliance, the challenge for future management is to identify the factors responsible in those children who had the greatest height gain. The more GH prescribed the greater the height gain that was seen. Therefore, a better response might be expected using a higher dosage and more frequent injections. This would agree with Ranke et al, who demonstrated the important role of GH dosage and the frequency of injections in the short term growth response to treatment. ${ }^{11}$

Those children who started treatment before 10 years of age grew significantly better, despite reaching final height 1 year younger than those starting after 10 years of age. This differs from the report of Nilsson et al, who failed to show a difference between the age of starting treatment and the change in height SDS. ${ }^{12}$ In our study, this change was also significantly related to the total time on GH treatment and the total dose of $\mathrm{GH}$ received. However, the younger children had a lower height SDS at the start of treatment and their increase in height SDS was greater than in the older group.

The children reported were treated with $\mathrm{GH}$ alone. Rosenfeld reported an $8 \mathrm{~cm}$ height gain using $\mathrm{GH}$ alone in children of a similar age, ${ }^{13}$ and we would expect children in the UK to have a similar increase if they were to receive similar doses and duration of treatment. Rosenfeld and others have reported even better growth when using different regimens, adding oxandrolone to GH treatment, and concluded that such regimens might give an even greater height gain. ${ }^{413}$

\section{Conclusions}

We analysed a decade of GH treatment in Turner syndrome in the UK. Even with suboptimal treatment, mean height gain was $5 \mathrm{~cm}$; when treatment was started prepubertally, younger children grew even more. We conclude 
that, in advising treatment with $\mathrm{GH}$ in girls with Turner syndrome today, greater height gain might be expected starting at an early age with $30 \mathrm{IU} / \mathrm{m}^{2} /$ week in six to seven injections each week.

It has been suggested that the way forward may be an evidence based treatment protocol with controlled intervention with different therapeutic agents and doses. ${ }^{4}$

This study would not have been possible without the data input and involvement of all the participating centres: Royal Manchester Children's Hospital, Manchester; Queen's Medical Centre, Nottingham; Addenbrooke's NHS Trust, Cambridge; Middlesex Hospital, London; Leeds General Infirmary, Leeds; Ninewells Hospital, Dundee; Royal Hospital for Sick Children, Edinburgh; Children's Hospital, Sheffield; Alder Hey Hospital, Liverpool; Royal Hospital for Sick Children, Glasgow; Roya nfirmary, Leicester; Children's Hospital, Birmingham; Roya Victoria Infirmary, Newcastle; John Radcliffe Hospital, Oxford; Royal Infirmary, Aberdeen; Hospital for Sick Children, Belfast; Royal Infirmary, Bristol; University Hospital of Wales, Cardiff; Great Ormond Street Hospital, London; Royal Victoria Hospital, Belfast; Southampton General Hospital, Southampton; Christie Memorial Hospital, Manchester; District General Hospital, Grimsby; City General Hospital, Stoke on Trent; Hospital, Grimsby, City General Hospital, Stoke on Trent LCPEM (Middlesen, London, Northampton General Hospital, Northampton; Newham General Hospital, London; St Bartholomew's Hospital, London; Royal Infirmary, Hull; Maidstone General Hospital, Maidstone; County Hospital, Hereford; Derriford Hospital, Plymouth; Royal Free Hospital, London.

1 Lyon AJ, Preece MA, Grant DB. Growth curve for girls with Turner syndrome. Arch Dis Child 1985;60:932-5.

2 Chu CE, Paterson WF, Kelnar CJ, Smail PJ, Greene SA, Donaldson M. Variable effect of growth hormone on growth and final adult height in Scottish patients Turner's syndrome. Acta Paediatr 1997;86:160-4.
3 Tillman V, Price DA, Bucknall JL, Clayton PE. Experience within the Manchester growth clinic of growth hormone treatment of girls with Turner syndrome: the influence of duration of Wikland $\mathrm{K}$, Ranke $\mathrm{MB}$, Turner perspective. Amsterdam: Elsevier, 1995:149-54.

4 Donaldson MD. Growth hormone therapy in Turner syndrome-current uncertainties and future strategies. Horm Res 1997;48(suppl 5):35-44.

5 Crock P, Werther GA, Wettenhall HN. Oxandrolone increases final height in Turner syndrome. 7 Paediatr Child Health 1990;26:221-4.

6 British National Formulary. London: British Medical Association and Royal Pharmaceutical Society of Great Britain, Number 34 (September 1997).

7 Van Teunenbroek A, de Muinck Keizer-Schrama SM, Stijnen T, et al. Yearly stepwise increments of the growth hormone dose results in a better growth response after four years in girls with Turner syndrome. Dutch working group on growth

8 Cole TL, Hall DMB. Screening for growth: towards 2000 [letter]. Arch Dis Child 1996;74:183.

9 Rochiccioli P, Chaussain JL. Final height in patients with Turner syndrome treated with growth hormone $(n=117)$. In: Albertsson-Wikland K, Ranke MB, eds. Turner syndrome in a life-span perspective. Amsterdam: Elsevier, 1995:123-8.

10 Van de Broek J, Massa GG, Attanasio A, et al. Final height after long-term growth hormone treatment in Turner synafter long-term growth hormone treat
drome. F Pediatr 1995;127:729-35.

11 Ranke MB, Guilbaud O, Lindberg A, Cole T. Prediction of the growth response in children with various growth disorders treated with growth hormone: analyses of data from the Kabi Pharmacia international growth study. International board of the Kabi Pharmacia international growth study. Acta Paediatr Suppl 1993;82(suppl 391):82-8.

12 Nilsson KO, Albertsson-Wikland K, Alm J, et al. Improved final height in girls with Turner's syndrome treated with growth hormone and oxandrolone. F Clin Endocrinol Metab 1996;81:635-40.

13 Rosenfeld RG, Attie KM, Frane J, et al. Growth hormone therapy of Turner syndrome: beneficial effect on adult height. F Pediatr 1998;132:319-24. 